\section{ACCELERATED SCREENING METHODS FOR PREDICTING LUBRICANT PERFORMANCE IN REFRIGERANT COMPRESSORS}

Quarterly Progress Reports

1 Octoter 1992 - 31 December 1992

1 January 1993 - 31 March 1993
RECEIVED

JUN 10 1993

OSTI

\author{
C. Cusano \\ Department of Mechanical \& Industrial Engineering \\ University of Illinois at Urbana-Champaign \\ Urbana, Illinois 61801
}

March 1993

Prepared for

The Air-Conditioning and Refrigeration Technology Institute

Under

ARTI MCLR Project Number 655-51600

This project is supported, in whole or in part, by U.S. Department of Energy grant number DE-FG02-91CE23810: Materials Compatibility and Lubricants Research (MCLR) on CFC-Refrigerant Substitutes, Federal funding supporting this project constitutes $93.67 \%$ of allowable costs. Funding from non-government sources supporting this project consists of direct cost sharing of $6.33 \%$ of allowable costs; and in-kind contributions from the air-conditioning and refrigeration industry.

\title{
MASTER
}

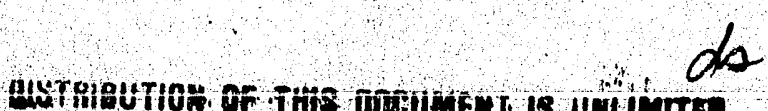




\section{DISCLAIMER}

The U.S. Department of Eriergy's and the air-conditioning industry's support for the Materials Compatibility and Lubricants Research (MCLR) program does not constitute an endorsement by the U.S. Department of Energy, nor by the air-conditioning and refrigeration industry, of the views expressed herein.

\section{NOTICE}

This report was prepared on account of work sponsored by the United States Government. Neither the United States Government, nor the Department of Energy, nor the Air-Conditioning and Refrigeration Technology Institute, nor any of their employees, nor any of their contractors, subcontractors, or their employees, makes any warranty, expressed or implied, or assumes any legal liability or responsibility for the accuracy, completeness, or usefulness of any information, apparatus, product or process disclosed or represents that its use would not infringe privately-owned rights.

\section{COPYRIGHT NOTICE}

By acceptance of this article the publisher and/or recipient acknowledges the right of the U.S. Government and the Air-Conditioning and Refrigeration Technology Institute, Inc. (ARTI) to retain a nonexclusive, royalty-free license in and to any copyright covering this paper. 


\title{
Quarterly Technical Progress Report \\ October 1992 - February 1993
}

\begin{abstract}
As the result of a thorough literature search and consultation with manufacturers of compressors, a specimen testing program is proposed to simulate specific contacts in components of compressors. Specimen testing will be conducted using a high pressure tribometer. Specific components to be simulated, with their approximate operating and environmental conditions, are identified. A list of references, related to compressors lubrication, friction and wear, is given in the Appendix.
\end{abstract}

\section{SCOPE}

The scope of this report is to propose a specimen testing program which serves as a basis for recommending a bench tester to screen lubricants of refrigerant compressors.

\section{PROPOSED SPECIMEN TESTING PROGRAM}

\section{A. Objective}

The main objective of this report is to recommend a testing program which will aid in the selection of an effective bench tester for screening lubricants used in compressors of air-conditioning and refrigeration systems.

\section{B. Introduction}

In working toward a final recommendation for a bench tester, the following approach has been proposed:

1. Thoroughly search the open literature for tribological data, both component and specimen, related to compressors of air-conditioning and refrigeration systems. 
2. Intoract with compressors manufacturers to determine which components are more likely to have tribological problems in practice.

3. Collect from the manufacturers as much tribological data as possible about these critical components. Among these data could be type of tribological failures, approximate operating and environmental conditions under which these failures occurred, materials in contact, contact geometry and surface topography.

4. From the data collected, select representative contact geometries to be tested. The maximum number of contact geometries would be four, i.e., point, line, conformal and area.

5. With input from manufacturers of compressors, select oils to be screened and refrigerants to be used.

6. Test the contact geometries with selected oil-refrigerant mixtures, using the high pressure tribometer simulating as closely as possible the operating and environmental conditions experienced by the corresponding components in the compressors.

7. Tribological effectiveness of each oil-refrigerant mixture will be compared to data obtained from component tests. If the latter tests do not exist, it is hoped that the compressors manufacturers, who have cooperated in Steps 2,3 and 5 above, will conduct these tests, with the same oil-refrigerant mixtures, for comparison purposes.

8. Recommendations concerning a specific bench test facility which can be used for accelerated oil screening will be based on the correlation obtained in Step 7.

This report focuses on items 1 through 5 since this portion of the research program is nearly complete. These items will be briefly discussed below in the order listed.

The literature search has been completed and a list of references pertinent to the lubrication of compressors of air-conditioning and refrigeration system is given in the Appendix. This list excludes those references which are already listed in the ARTI refrigerant database. As expected, in this area, the number of references in the open literature is rather limited.

In order to better understand future lubricity problems envisioned by compressor manufacturers, as well as present method for screening lubricants and testing compressors, four manufacturers were visited. These visits were to Trane on 12/1/92 (Mr. Richard Ernst, host), Tecumseh on 12/14/92 (Dr. Keshav Sanvordenker, host), Carrier on 1/11/93 (Mr. William Walter, host) and Copeland on 1/12/93 (Mr. Sonny Sundaresan, host). In all of these visits, in addition to the hosts, a number of other people responsible for research, technology, design and reliability of screw, scroll, rotary and reciprocating compressors were present during the meetings. The 
discussion mainly focused on lubrication failure modes of components, test methodologies used for approval of a lubricant and general lubrication requirements in compressors. The objectives of this report are to give an overview of these visits and to suggest a testing program which will aid in the selection of an effective bench tester for screening lubricants.

\section{General Observations Derived From Visits}

1. Iribological Components. In compressors of air-conditioning and refrigeration systems, there are numerous tribo-contact pairs which may fail. Some of the more critical of these contact pairs are:

a. Wrist pin-bearing contact in reciprocating compressors.

b. Vane-roller contact in rotary compressors.

c. Thrust bearing-Oldham coupling, involute flanks and tip seals contacts in scroll compressors.

d. Male-female rotors interface and slide valve contacts in screw compressors.

A number of other tribo-contacts, such as those found in journal bearings and especially those in rolling element bearings, are presently not perceived as being problem areas.

2. General Lubrication Requirements and Test Methodology. Past lubrication performance, using mineral or alkylbenzene oils, has not been of great concern to manufacturers of compressors. These lubricants performed well with both R-12 and R-22 and decisions concerning which oil to use were often based on price rather than their lubricity. As the result of miscibility problems of these oils with ozone-safe refrigerants, a niajor effort is underway to identify synthetic lubricants which can be used with such refrigerants. The main lubricant candidate at this time is the ester family, especially pentaerythritol ester. A number of steps are followed in selecting a lubricant for a compressor. These steps can vary somewhat depending on the manufacturers. However, many of the steps are quite similar among the companies visited. A representative set of chronological steps is given below.

a. Initial lubricant screening using specimen tesiers. Even though most of this screening is done in-house, independent laboratories are also used. The most popular bench tester is the Falex pin and vee block with refrigerants fed through the oil. Tests are generally conducted at atmospheric pressure in a controlled environment. Various materials combinations are used for the pin and vee block. Other specimen bench testers used are the four-ball and block-on-cylinder machines. 
b. Accelerated or abuse testing using compressors. These tests can run from one to several months under various conditions. Tests at relatively high loads and/or high temperatures, or under refrigerantrich, oil-refrigerant mixtures are the most common. After each test, the compressors are taken apart and critical tribo-contacts as well as the lubricant are carefully evaluated.

c. Limited field trials to observe lubricant performance under actual operating conditions.

d. After passing the steps above, the lubricant is accepted for general use.

e. As a general rule, it is preferable to use one lubricant for all compressors made by a manufacturer.

\section{Specimen Testing Program.}

As per the original proposal, the recommendation of a specimen bench tester to screen lubricants for compressors will be based on data obtained from a high pressure tribometer (HPT). The tribological evaluation will be based on friction and wear measurements plus examination of worn surfaces by means of $\mathrm{X}$-ray Photoelectron Spectroscopy (XPS). The main advantage of the HPT over more standard bench testers is its capability of providing a controlled pressure and temperature environment during a test. Complexity and high costs are its main disadvantages. The emphasis of the testing program is to determine if the HPT can accurately predict lubricant performance in compressors by conducting tests under conditions which approximately simulate component operation. In order to determine if simpler and/or less costly bench testers can predict lubricant performance to the same degree as the HPT, a comparison will be made between data obtain on the Falex pin and vee block tester and the HPT to those obtained from component (compressor) testing. A detailed description of the proposed testing program is given below.

1. Compressors and their Critical Contents to be Studied. Even though not all data are presently available, the following compressors and tribocontacts are the main candidates for study in this program:

a. Reciprocating compressor: conformal contact of wrist pin and bearing.

b. Rotary compressor: counterformal contact of vane and roller.

c. Scroll compressor: area contact of thrust bearing and Oldham coupling.

d. Screw compressor: counterformal contact of male and female rotors. 
2. Qil-Befrigerant Mixtures to be Tested. Baseline data will be obtained by using R-12 and R-22 with mineral or alkylbenzene oils. The specific oils which will be used will correspond to those which have been or are being used in each compressor. The new oil-refrigerant mixtures will be mainly composed of R-32 blends and R-134a with ester oils, especially the pentaerythritol ester. Again, the specific oil-refrigerant mixture which will be used in the specimen testing program will be the same as the mixture used to obtain component data from compressor tests.

3. Materials for Contact Pairs. Since data obtained from the HPT will be compared to data obtained from Falex pin and vee block as well as to those obtained from component testing, two separate set of material contact pairs will be examined since materials used for the Falex tests might not correspond to those used in the actual components. To compare results obtained from the HPT to those of the Falex, the following material contact pairs will be tested:

a. $\quad 380$ die cast aluminum with hardened steel.

b. 380 die cast aluminum with gray cast iron.

c. Hardened gray cast iron with hardened steel.

d. Hardened steel with hardened steel.

The line contact geometry, load and oil-refrigerant mixture used in obtaining the Falex data will also be used to get data from the HPT. The latter data, however, will be obtained under environments and kinematic conditions which are more representative of actual components operation.

To compare results from the HPT with those obtained from compressor testing, the following material contact pairs will be tested:

a. 380 die cast aluminum with hardened steel, in a conformal contact, to simulate the wrist pin-bearing contact of reciprocating compressors.

b. Mild steel with itself, in a line contact, to simulate the male-female rotors interface of screw compressors.

c. Sintered ferrous metal with itself, in a line contact, to simulate the vane-roller contact in rotary compressors.

d. Mild steel with Norplex, in an area contact, to simulate the thrust bearing-Oldham coupling in scroll compressors.

All the operating and environmental conditions for the materials contact pairs above will approximately simulate component operation. 
4. Qperating and Environmental Conditions. Approximate operating and environmental conditions which will be used to test the contacts under item 3 above are given below.

\begin{tabular}{|l|l|l|l|l|}
\hline $\begin{array}{l}\text { Operating and } \\
\text { Environmental } \\
\text { Conditions }\end{array}$ & $\begin{array}{l}\text { Wrist Pin- } \\
\text { Bearing Contact: } \\
\text { Reciprocating } \\
\text { Compressor }\end{array}$ & $\begin{array}{l}\text { Male-Female } \\
\text { Imterface Con- } \\
\text { tact: Screw } \\
\text { Compressor }\end{array}$ & $\begin{array}{l}\text { Vane-Roller } \\
\text { Contact: Rotary } \\
\text { Compressor }\end{array}$ & $\begin{array}{l}\text { Thrust Bearing- } \\
\text { Oldham Coupling } \\
\text { Contact: Scroll } \\
\text { Compressor }\end{array}$ \\
\hline $\begin{array}{l}\text { Pressure or } \\
\text { Load/Unit } \\
\text { Length }\end{array}$ & $2500 \mathrm{psi}$ & $40-120 \mathrm{lb} / \mathrm{in}$. & $1300 \mathrm{lb} / \mathrm{in}$. & $330 \mathrm{psi}$ \\
\hline Type of Motion & Oscillatory & Unidirectional & Oscillatory & Oscillatory \\
\hline Speed & 14 in./s (max) & $40-80$ in./x & 20 in./s (max) & 20 in./s (max) \\
\hline $\begin{array}{l}\text { Angular } \\
\text { Amplitude }\end{array}$ & $\pm 50^{\circ}$ & - & - & \\
\hline $\begin{array}{l}\text { Angular } \\
\text { Frequency }\end{array}$ & $58 \mathrm{~Hz}$ & - & - & $29-58 \mathrm{~Hz}$ \\
\hline $\begin{array}{l}\text { Environ. } \\
\text { Pressure }\end{array}$ & $4.5-7 \mathrm{psi}$ & $50-400 \mathrm{psi}$ & $225 \mathrm{psi}$ & $85 \mathrm{psi}$ \\
\hline Environ. Temp. & $325-350^{\circ} \mathrm{F}$ & $50-250^{\circ} \mathrm{F}$ & $175^{\circ} \mathrm{F}$ & $50^{\circ} \mathrm{F}$ \\
\hline
\end{tabular}

It should be noted that not all of these operating and environmental conditions can be simulated in the HPT. The maximum operating temperature and pressure of the HPT are $300^{\circ} \mathrm{F}$ and $250 \mathrm{psi}$, respectively, while the maximum angular frequency is $5 \mathrm{~Hz}$. It is felt, however, that these discrepancies will rot significantly affect the results and conclusions drawn from this research program. For the purpose of repeatability and to effectively compare data obtained using different lubricants, all tests will be conducted such that the sliding contacts are submerged in the lubricants. Finally, the information given in this report is not complete since all the data requested from the various manufacturers of compressors have not been received or are not available at this time. It is hoped that these data can be obtained in the near future. 


\section{COMPLIANCE WITH AGREEMENT}

The University of Illinois at Urbana-Champaign has complied with all terms of the grant agreement.

\section{PRINCIPAL INVESTIGATOR AND STUDENTS EFFORT}

Cristino Cusano (Principal Investigator) has denoted approximately 10 hours a week to this project.

Carl Poppe and Hyung Yoon have each devoted approximately 20 hours a week to this project. A large proportion of the students' time was spent on familiarization with the high presure tribometer, designing specimen holders, designing the instrumentation to measure the contact resistance between the rubbing specimens and thinking about designing the experiments. 


\section{APPENDIX}

References Related to Refrigerant Compressor Lubrication

Anon, Oll-Flooded Propylene Refrigeration Screw Compressor, Kobelco Technol, August 1987, volume 2, number 2, page 63.

J. J. Baustian, M. B. Pate and A. E. Bergles, Properties of Oil - Refrigerant Liquid Mixtures with Applications to Oll Concentration Measurement: Part 1 Thermophysical and Transport Properties, Transactions, American Society of Heating, Refrigerating, and Air-Conditioning Engineers (ASHRAE), volume 92, pages 74-92, Jan. 1986.

L. Brodsky, J. Zielinski, G. Perrault, R. Schmaus, Commerclal Experlence with Diester Based Synthetic Industrial Lubricants, Iron and Steol Engineer, December 1984, volume 61, number 12, pages 41-46.

N. E. Carpenter, Retronitting HFC-134a into Existing CFC-12 Systems, International Joumal of Refrigeration, July 1992, volume 15, number 6 , pages 332-339.

H. Cawte, Effect of Lubricating Oil Contamination on Condensation in Refrigerant R-22, Intemational Journal of Energy Research, June 1992, volume 16, number 4, pages 327-340.

B. A. Davis, T. Sheiretov and C. Cusano, Tribological Evaluation of Contacts Lubricated by Oll = Refrigerant Mixtures, Proceedings of the 1992 Intermational Compressor Engineering Conference, Purdue University, West Lafayette, Indiana, volume 2, pages 477-488. July 14-17, 1992.

A. Factor and P.M. Miranda, An Investigation of the Mechanism of the R12 Oll Steel Reaction, Wear, October 21, 1991, volume 150 , number 1-2, pages 41-58.

M. Fukuta, M. Tanaka, T. Shimizu, T. Yanagisawa, Analysis of Oil Film on Vane Sides of Vane Compressors, Transactions of the Japanese Society of Mechanical Engineers, June 1991, volume 57, number 538, pages 2007-2012.

I. G. Fuks and V. L. Lashkhi, Blends of Petroleum and Synthetic Olis - Properties and Features of Application, Chemistry and Technology of Fuels and Oils, March-April 1990, volume 26, number 3-4, pages 133-140.

N. J. Hewitt, J. T. McMullan, N. E. Murphy and N. Shafaghian, A Solubility Equation for R22 Oil Mixtures, Intemational Joumal of Energy Research, December 1991, volume 15, number 9, pages 763-768.

D. W. Hughes, J.T. McMullan, K.A. Mawhinney and R. Morgan and B. L. Sutcliffe, Lubricant Related Problems with Heat Pumps, Proceedings of the 1980 Intemational Compressor Engineering Conference, Purdue University, West Lafayette, Indiana, 1980, pages 156-163.

D. P. Huttenlocher, Bench Scale Test Procedure for Hermetic Compressor Lubricants, Transactions, American Society of Heating, Refrigerating, and Air-Conditioning Engineers (ASHRAE), volume 11, number 6, page 85, June 1969.

S. Kitaichi, S. Sato, R. Ishidoya, T. Machida, Tribological Analysis of Metal Interface Reactions in Lubricant Olls/CFC-12 and 
HFC-134a System, Proceedings of the 1990 ASHRAE-Purdue CFC Conference, Purdue University, West Lafayette, Indiana, pages 153-162, 1990.

H. H. Kruse and M. Schroeder, Fundamentals of Lubrication in Refrigerating Systems and Heat Pumps, International Joumal of Refrigeration, volume 8, November 1985, pages 347-355.

Kiyoharu Kutsuna, Yoshimitsu Inoue and Takehito Mizutani, Real Time Oll Concentration Measurement in Automotive Air Conditioning by Ultraviolet Light Absorption. Society of Automotive Engineers Technical Paper Series, 910222.

N. Masuda, Some Evaluation Results of HFC-134a/ PAG Mixtures for Refrigeration, Proceedings of the 1990 ASHRAE - Purdue CFC Conference, 1990, pages 297-307.

J. T. McMullan, N. J. Hewitt, A. J. Masson, N. E. Murphy, Influence of Oll Viscosity and Refrigerant Quality on Evaporator Performance, Intemational Joumal of Energy Research, September 1992, volume 16, number 7, pages 567-581.

K. Mizuhara, M. Akei and T. Matsuzaki, The Friction and Wear Behavior in a Controlled Alternative Refrigerant Atmosphere, Presented at the ASME/ STLE Tribology Conference, San Diego, CA., Oct. 18-21, 1992. STLE paper 92-TC-3B-3.

S. F. Murray, R. L. Johnson, M. A. Swikert, Difluorodichloromethane as a Boundary Lubricant for Steel and Other Metals, Mechanical Engineering, March 1956, volume 78, pages 233-236.

C. Nolden, Synthetic Lubricants, Plant Engineering, May 1985, volume 39, number 9, pages $30-41$.

V. A. Repin, Method for Ralsing the Wear
Resistance of the Cylinder Surface of a Reclprocating Compressor, Soviet Engineering Research, September 1987, volume 7 , number 9 , pages 33-34.

T. Sabusawa, Recent Developments in Refrigeration Compressors and Lubrication, Japanese Joumal of Tribology, January 1990, volume 35, number 9, pages 1061-1067.

K. S. Sanvordenker, Durability of R-134A Compressors - The Role of the Lubricant, Transactions, American Society of Heating, Refrigerating, and Air-Conditioning Engineers (ASHRAE), volume 33, number 2, page 42, Feb. 1991.

A. Schelling, H. H. Kausch and A. C. Roulin, Friction Behaviour of Polyethereketone Under Dry Reciprocating Movement, Weär, November 30, 1991, volume 151, number 1 , pages 129-142.

H. Seiki, Recent Trend of Compressor Oils, Joumal of Japanese Society of Tribologists, 1990 , volume 35, number 9, pages 615-620.

A. V. Shiichuk and D. V. Kolesnikova, Oxidized Low Molecular Weight Polyethylene as a Lubricant Refrigerant Composition, Chemistry and Technology of Fuels and Oils, July-August 1991, volume 27, number 7-8, pages 352-355.

H. O. Spauschus and D. R. Henderson, New Methods of Determining Viscosity and Pressure of Refrigerant/Lubricant Mixtures, Procerdings of the 1990 ASHRAE - Purdue CFC Conference, 1990, pages 173-196.

N. Stosic, L. J. Milutinovic, K. Hanjalic and A. Kovacevic, Investigation of the influence of Oll Injection upon the Screw Compressor Working Process, Intemational Joumal of Refrigeration Reviow, 1992, volume 15, number 4, pages 206-220.

S. G. Sundaresan, Alternate Refrigerants 
and Lubricants for Refrigeration Compressors - Status on CFC-12 and R-502 Replacements, Written for the XVIIt Intermational Congress of Refrigeration, Paper No. 151, August 10-17, 1991.

S. G. Sundaresan, Status Report on Polyalkylene Glycol Lubricants for Use with HFC-134a in Refrigeration Compressors, Procerdings of the 1990 ASHRAE - Purdue CFC Conference, 1990, pages 138-144.

A. Tanka, Effects of Alternative Refrigerant on Friction and Wear of Nylon and Polyacetar, Proceedings of JAST Trib. Conference, Tokyo, May i991, E-20.

J. C. Tolfa, Synthetic Lubricants Suitable for use in Process and Hydrocarbon Gas Compressors, Lubrication Engineering, April 1991, volume 47, number 4, pages 289-295.

T. Yanagisawa, T. Shimizu, Foaming of Refrigerating Oll in a Rolling Piston Type Compressor, International Journal of Refrigeration, January 1986, volume 9 , number 1, pages 17-20.

T. Yanagisawa, T. Shimizu and M. Fukuta, Foaming Characteristics of an OllRefrigerant Mixture, Intemational Joumal of Refrigeration Review, May 1991, volume 14, number 3 , pages $132-136$.

Non-English Entries:

R. Heide, Properties of Refrigerating Machine Oll Luefrigol XK 30 and Its Mixtures with Refrigerants, Luff and Kaeltetechnik, volume 23, number 3, 1987 , pages 160-162. (German)

Abstract: A description is given of essential physical properties of the newly developed refrigerating machine oils Luefrigol XK 30. Graphs plot the dependence of viscosity, steam pressure and density on the temperature and concentration of the oil mixtures with refrigerant R13, R22 and R13B1.

H. Lippold, S. Reinhold, Laboratory Tests of the Tribological Characteristics of Refrigerating Machine Olls Under the Influence of Refrigerants, Luft and Kaeltetechnik, volume 23, number 4, 1987, pages 218-220. (German)

Abstract: To judge the tribological behavior of refrigerating oils, an apparatus was built up on the ALMEN-WIELAND principle so as to make tests under the simultarieous influence of various refrigerants. In order to assess the oil grades, reference was made to the load bearing capacity of steel/steel test bearings. The test results obtained from various oils with $R 12$ and $R 22$ are reported.

U. Todsen, Refrigerating Machinery Oil Better Performance with Synthetic Lubricants? Investigatlons Concerning the Thermal stability of Refrigerator Olls. Ki Klima Kaelte Heizung, volume 15, number 4, April 1987, pages 186-189. (German)

Abstract: Considerable demands are made on refrigerator oils during operation. High temperature differences in the refrigerator, interactions between oil and refrigerant, and contact with different materials combine to make difficult operating conditions. The article lists the requirements to be met by refrigerator oils, mentions the commercially available oils and presents investigations concerning the thermal stability of oils, which is an essential influencing parameter of troublefree refrigerator operation.

T. Yanagisawa, T. Shimizu, Study of the Flow Characteristics of Refrigerating OII Dissolved with Refrigerant, Nippon Kikai Gakki Ronbunshu, July 1986, volume 52, number 479, pages 2581-2587.

(Japanese)

Abstract: In a refrigerating compressor, refrigerating oil lubricates moving parts and seals clearances. But its characteristics are much affected by the presence of the refrigerant. This study analyzed the channel 
flow sharacteristics of refrigerating oil dissolved with refisgerant 22 . In theoretical analyses the apparent properties of the flow were estimated; and using theris, the flow modelled as a single phase flow. The pressure and temperature profiles at the channel and the flow rate were calculated theoretically and compared with experimental results which were measured using a model channel. 

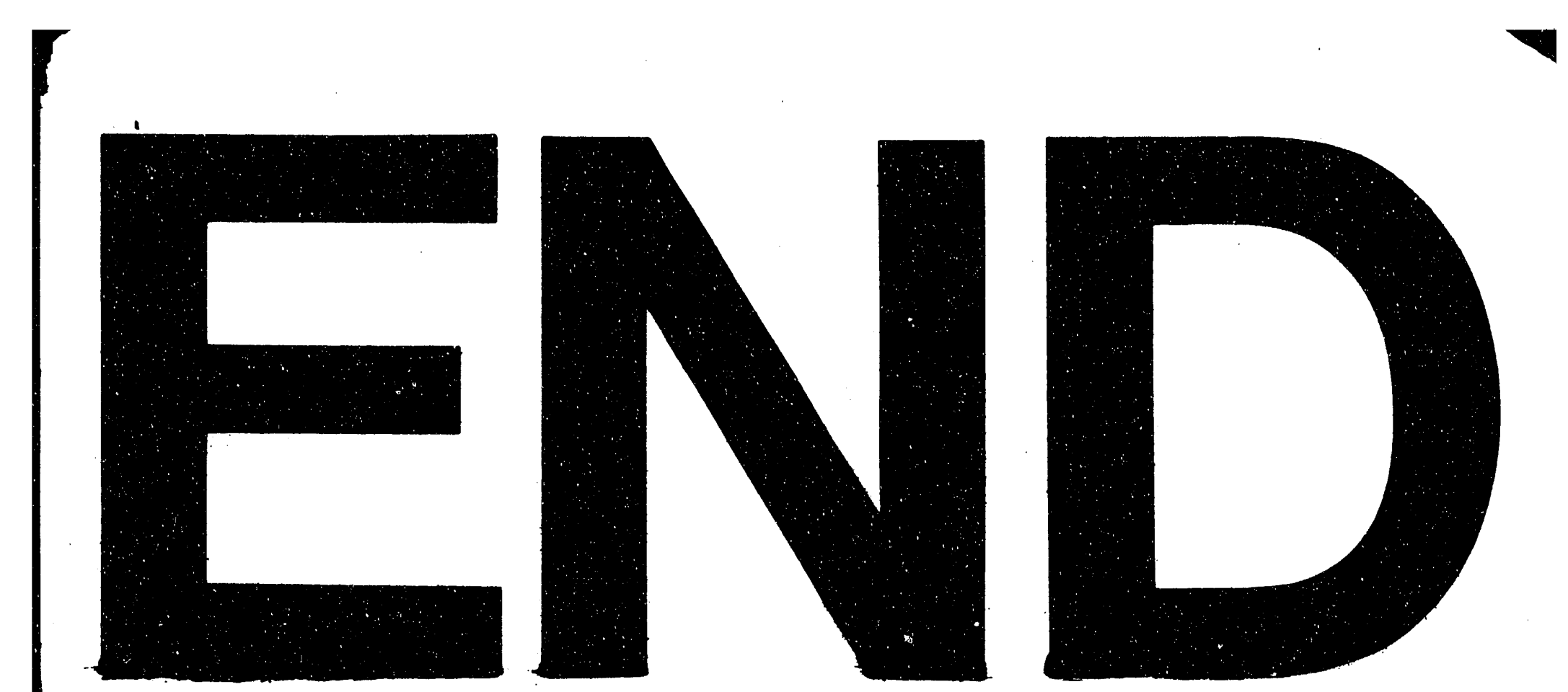

종
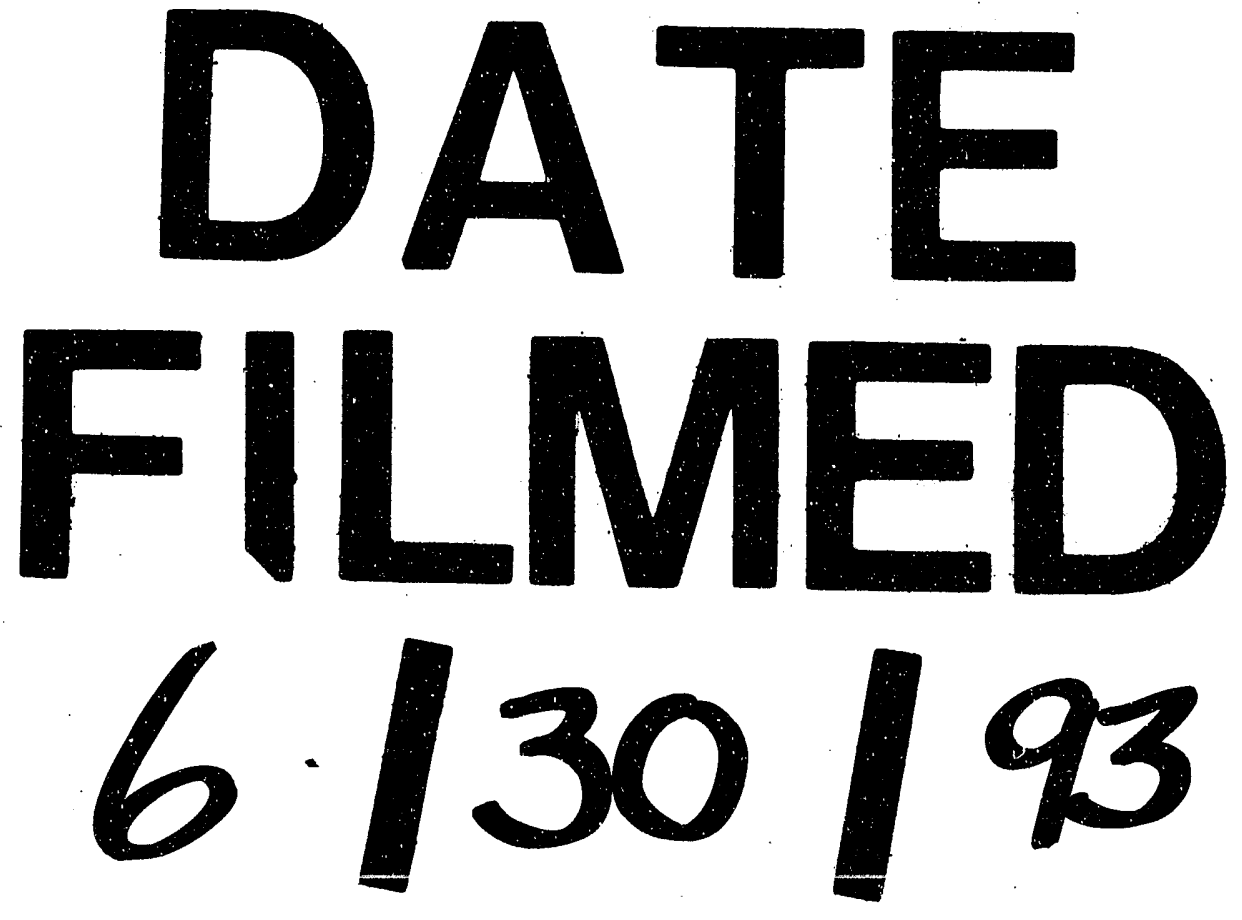
